Check for updates

Cite this: RSC Adv., 2017, 7, 21422

Received 20th February 2017 Accepted 10th April 2017

DOI: $10.1039 / c 7 r a 02092 a$

rsc.li/rsc-advances

\section{Effect of post-heat treatment on the photocatalytic activity of titanium dioxide nanowire membranes deposited on a $\mathrm{Ti}$ substrate}

\author{
Ying Chang, (D) abc Chonggang Wu, ${ }^{\text {abc }}$ Huihu Wang, ${ }^{\text {abc }}$ Yan Xiong, ${ }^{\text {abc }}$ Yuan Chen, ${ }^{\text {abc }}$ \\ Kai Ke, ${ }^{\text {abc }}$ Yao $\mathrm{He}^{c}$ and Shijie Dong*abc
}

Titanium dioxide nanowire membranes have been synthesized by a hydrothermal growth on the surfaces of Ti substrates in a $12 \mathrm{M} \mathrm{NaOH}$ aqueous solution at $160{ }^{\circ} \mathrm{C}$ for $24 \mathrm{~h}$, followed by ion-exchange with $0.5 \mathrm{M}$ $\mathrm{HCl}$ aqueous solution and subsequent heat treatment such as calcination or a second hydrothermal treatment. The as-prepared $\mathrm{TiO}_{2}$ nanowires as well as their precursor were characterized by field emission scanning electron microscopy (FE-SEM), thermogravimetry-differential thermal analysis (TGDTA), X-ray diffraction (XRD), the Brunauer-Emmett-Teller (BET) method, ultraviolet-visible (UV-Vis) spectrophotometry, transmission electron microscopy (TEM) and energy dispersive X-ray (EDX) spectrometry. FE-SEM observations indicated that the $\mathrm{TiO}_{2}$ nanowires were 50-250 nm in diameter and up to several dozens of microns in length. TG-DTA and XRD results demonstrated that the crystalline phases of the nanowires obtained from calcinations of their precursor at different temperatures above $350{ }^{\circ} \mathrm{C}$ consisted mostly of anatase. BET, UV-Vis, TEM and EDX results showed that the nanowires obtained upon calcination of their precursor at $550{ }^{\circ} \mathrm{C}$ had the greatest degradation efficiency for Rhodamine-B, and that, at the same temperature of $250{ }^{\circ} \mathrm{C}$, the hydrothermal treatment process of $\mathrm{TiO}_{2}$-precursor nanowires had a more significant effect on the photocatalytic activity of the resulting $\mathrm{TiO}_{2}$ nanowires than the calcination.

\section{Introduction}

Due to economic disparity, rapid urbanization, industrialization, and population growth, ${ }^{1}$ there are growing concerns about water availability and the strategies necessary to deliver potable water with the growing demands for clean water sources. ${ }^{2,3}$ Industrial waste water is an extremely serious problem of water pollution, ${ }^{2}$ as it contains various compositions of constituent pollutants which are often unknown. Usually, these pollutants cannot be self-cleaned in the environment, ${ }^{4}$ the artificial treatment of which is complicated and costly.

$\mathrm{TiO}_{2}$ is a wide-band semiconductor material with gaps of $3.2 \mathrm{eV}$ for anatase and $3.0 \mathrm{eV}$ for rutile. ${ }^{5-7}$ Degussa P25, a commercial $\mathrm{TiO}_{2}$ polycrystalline nanopowder, ${ }^{8}$ is chemically inert and cost-effective, and exhibits satisfactory photocatalytic activity. ${ }^{9}$ Therefore, it has widely been used in photocatalytic water-treatment, although the separation of $\mathrm{TiO}_{2}$ nanoparticles from the treated water has high energy costs. ${ }^{10}$

${ }^{a}$ Hubei Provincial Key Laboratory of Green Materials for Light Industry, Hubei University of Technology, Wuhan 430068, China. E-mail: cgwu@mail.hbut.edu.cn ${ }^{b}$ Collaborative Innovation Center of Green Light-weight Materials and Processing, Hubei University of Technology, Wuhan 430068, China

${ }^{c}$ School of Materials and Chemical Engineering, Hubei University of Technology, Wuhan, 430068, China
Recently, more focus has been directed to the technology of preparing $\mathrm{TiO}_{2}$ nanowire/nanobelt thin membranes, which show superior performance to $\mathrm{TiO}_{2}$ nanoparticles. ${ }^{11,12}$ For example, $\mathrm{TiO}_{2}$ nanowires/nanobelts can minimize the release of nanomaterials into effluents during their self-assembled formation of membranes. ${ }^{13}$ As more and more studies are focused on this new technology, ${ }^{14}$ various methods to obtain $\mathrm{TiO}_{2}$ nanowire/nanobelt membranes have been developing and improving. ${ }^{15}$ In the past decade, great efforts ${ }^{1-19}$ were focused on the effects of hydrothermal parameters on the compositions and morphologies and clarification of the sequential events in the formation process of titanate nanotubes/nanowires/nanobelts. However, to our knowledge, nobody particularly investigated the preparation of $\mathrm{TiO}_{2}$ nanowires via a second hydrothermal process.

In this work, we report the synthesis of $\mathrm{TiO}_{2}$-precursor nanowires by a hydrothermal growth on the surfaces of $\mathrm{Ti}$ substrates, ${ }^{20}$ followed by the use of different heat-treatment methods (i.e. calcination and a second hydrothermal) on the synthesized precursor to obtain $\mathrm{TiO}_{2}$ nanowires. Analysis of the experimental results demonstrates that the $\mathrm{TiO}_{2}$ nanowires obtained upon the second hydrothermal treatment of their precursor possess higher photocatalytic activity than upon the calcination. 


\section{Experimental}

\section{Materials}

Titanium foil with purity greater than $99.5 \%, \mathrm{NaOH}, \mathrm{HCl}$ and ethanol were purchased from Sinopharm Chemical Reagent Co., Ltd, China and used as starting materials without further purification, and deionized water purified by ion exchange was used for solution preparation and synthesis.

\section{Preparation}

$\mathrm{TiO}_{2}$ nanowires were synthesized in a $\mathrm{NaOH}$ aqueous solution via hydrothermal growth on the surfaces of titanium foil $(1 \mathrm{~mm}$ thick). In detail, a $20 \times 20 \mathrm{~mm}^{2}$ piece of titanium foil was washed sequentially with ethanol and deionized water, then placed in a $100 \mathrm{~mL}$ Teflon-lined pressure vessel filled with $50 \mathrm{~mL}$ of $12 \mathrm{M} \mathrm{NaOH}$ aqueous solution. After heating the vessel at $160{ }^{\circ} \mathrm{C}$ for $24 \mathrm{~h}$, a thick, white cotton-like membrane of sodium titanate nanowires was obtained on each side of the titanium foil surface. ${ }^{6}$ The nanowires were randomly oriented and entangled together (i.e. intertwined) to form macroporous structured membranes. The titanium foil covered with the nanowire membranes was washed in deionized water, and then immersed in a $0.5 \mathrm{M} \mathrm{HCl}$ aqueous solution at $50{ }^{\circ} \mathrm{C}$ for $12 \mathrm{~h}$ to effectively transform $\mathrm{Na}_{2} \mathrm{Ti}_{3} \mathrm{O}_{7}$ nanowires into $\mathrm{H}_{2} \mathrm{Ti}_{3} \mathrm{O}_{7}$ nanowires via ion-exchange of $\mathrm{Na}^{+}$with $\mathrm{H}^{+}{ }^{6}$ The membranes were then peeled off the Ti foil using a knife and again washed in deionized water until the $\mathrm{pH}$ value of the washing solution was neutral. Finally, both the $\mathrm{TiO}_{2}$-precursor nanowire membranes obtained were air dried at $70{ }^{\circ} \mathrm{C}$ overnight (denoted as Sample A), and then heated with different post-heat treatments to obtain the resulting $\mathrm{TiO}_{2}$ nanowire membranes. The different post-heat treatments included direct calcination at different temperatures $\left(250,350,450,550\right.$ and $650{ }^{\circ} \mathrm{C}$ ) for $2 \mathrm{~h}$ (denoted as Samples B, C, D, E and F, respectively), and a second hydrothermal treatment at $250{ }^{\circ} \mathrm{C}$ for $2 \mathrm{~h}$ (denoted as Sample G) which was similar to the previous hydrothermal procedure except without $\mathrm{NaOH}$.

\section{Characterizations}

Surface morphologies of the as-prepared $\mathrm{H}_{2} \mathrm{Ti}_{3} \mathrm{O}_{7}$ precursor nanowires and of the $\mathrm{TiO}_{2}$ nanowires upon the post-heat treatments of the precursor nanowires were analyzed on a FEI, Quanta 450 field-emission scanning electron microscope (FESEM), operating at $7 \mathrm{kV}$. Data, obtained from a Shimadzu DTG$50 \mathrm{H}$ thermogravimetry-differential thermal analysis (TG-DTA) thermal analyzer, revealed the phase transformation temperature ranges required for designing the sintering program. Powder X-ray diffraction (XRD) patterns of $\mathrm{TiO}_{2}$ nanowires as well as of their precursor nanowires were recorded on a Bruker, D8 Advance powder X-ray diffractometer with $\mathrm{CuK} \alpha$ radiation (Si internal standard method), at a $2 \theta$ scan range of $5-60^{\circ}$ and a scan speed of $2^{\circ} \mathrm{min}^{-1}$. The specific surface areas of the samples were determined with Quantachrome instruments, NOVA 2200 specific surface area analyzer by the Brunauer-Emmett-Teller (BET) method using the $\mathrm{N}_{2}$ adsorption data (as shown in Table 1). Absorption spectra of the samples were recorded with a Hitachi,
Table 1 Specific surface areas measured by the BET method for the $\mathrm{H}_{2} \mathrm{Ti}_{3} \mathrm{O}_{7}$ precursor (Sample A), the $\mathrm{TiO}_{2}$ nanowires synthesized by calcinations for $2 \mathrm{~h}$ at temperatures of $250,350,450,550$ and $650^{\circ} \mathrm{C}$ (Samples B, C, D, E and F, respectively) and by hydrothermal treatment for $2 \mathrm{~h}$ at $250{ }^{\circ} \mathrm{C}$ (Sample G)

\begin{tabular}{ll}
\hline Samples & $\begin{array}{l}\text { Specific surface } \\
\operatorname{areas~}\left(\mathrm{m}^{2} \mathrm{~g}^{-1}\right)\end{array}$ \\
\hline A & 19.205 \\
B & 18.706 \\
C & 17.926 \\
D & 16.823 \\
E & 15.621 \\
F & 12.988 \\
G & 21.868
\end{tabular}

U-3900 ultraviolet-visible (UV-Vis) spectrophotometer using $\mathrm{BaSO}_{4}$ as a reflectance standard. High resolution transmission electron microscopy (HRTEM) observation and selected area electron diffraction (SAED) were carried out with a JOEL JEM 2100 microscope. To prepare the HRTEM specimens, the powder samples were first dispersed ultrasonically in acetone, and then one drop of the suspension was placed on a carbon-film-coated copper grid and allowed to dry in air before the specimens were finally transferred onto the microscope. An Oxford energy dispersive X-ray (EDX) spectrometer was used to analyze the elemental composition of the $\mathrm{TiO}_{2}$ nanowire membranes prepared.

\section{Photocatalytic activity measurements}

The photocatalytic activity of the $\mathrm{TiO}_{2}$ nanowire membranes was evaluated by monitoring the degradation efficiency of a Rhodamine-B (RhB) dye aqueous solution ( $20 \mathrm{~mL}$ of $5 \mathrm{mg} \mathrm{L}^{-1}$ ). All the tests were performed using a $300 \mathrm{~W}$ Xenon lamp, which emits both ultraviolet (UV) and visible light; during the assay, 2 $\mathrm{mL}$ of the solution was extracted at $10 \mathrm{~min}$ intervals, the $\mathrm{RhB}$ concentration of which was then measured using a UV-Vis spectrophotometer (JASCO, V-560). The degradation efficiency was calculated as $\left(C_{0}-C\right) / C_{0}$, where $C_{0}$ is the initial concentration of the $\mathrm{RhB}$ solution (i.e. $5 \mathrm{mg} \mathrm{L}^{-1}$ ) and $C$ the remaining concentration of RhB upon degradation for $1 \mathrm{~h}$.

\section{Results and discussion}

Effect of post-heat treatment on specific surface area of $\mathrm{TiO}_{2}$ nanowires

Fig. 1 shows the FE-SEM images of the as-synthesized $\mathrm{TiO}_{2}$ precursor nanowires (Fig. 1a) as well as of the $\mathrm{TiO}_{2}$ nanowires obtained upon two different post-heat treatments (i.e. calcinations and hydrothermal) of the precursor at the same temperature and time $\left(250{ }^{\circ} \mathrm{C}\right.$ for $\left.2 \mathrm{~h}\right)$. As expected, fibrous structures with a typical diameter of 50-250 $\mathrm{nm}$ and a length of several dozens of microns were observed for both the $\mathrm{TiO}_{2}$ and its precursor nanowires. We found that the structure of both the $\mathrm{TiO}_{2}$ nanowires underwent little changes after post-heat treatments of their precursor. Compared with the $\mathrm{TiO}_{2}$ nanowires 


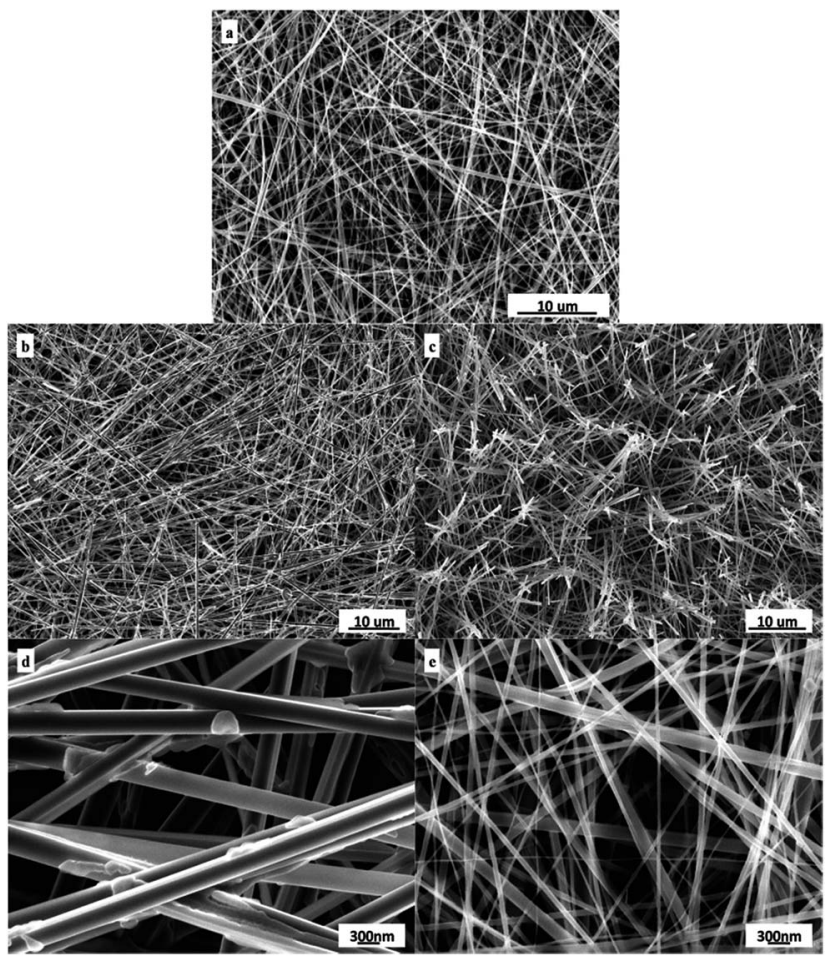

Fig. 1 Morphologies observed by FE-SEM of (a) the as-synthesized $\mathrm{H}_{2} \mathrm{Ti}_{3} \mathrm{O}_{7}$ (precursor of $\mathrm{TiO}_{2}$ nanowires) and the $\mathrm{TiO}_{2}$ nanowires prepared from ( $b$ and $d$ ) the calcination and from (c and e) the hydrothermal treatment of the $\mathrm{TiO}_{2}$ precursor nanowires at $250{ }^{\circ} \mathrm{C}$ for $2 \mathrm{~h}$.

obtained from the direct calcination of the precursor (Sample B) (Fig. $1 \mathrm{~b}$ and d), the $\mathrm{TiO}_{2}$ nanowires obtained from the hydrothermal treatment of the precursor (Sample G) were quite cleaner with less contamination on their surfaces and smaller in diameter (Fig. 1c and e). At some locations in Sample B, a fraction of the $\mathrm{TiO}_{2}$ nanowires seemed to be joined (or aggregated) with each other, which might decrease their specific surface area (Fig. 1d); apparently, this aggregation behavior occurred little in Sample G. Moreover, the nanowires in Sample G exhibited a distinctly smaller diameter than those in Sample B. These jointly demonstrated that the specific surface area of the $\mathrm{TiO}_{2}$ nanowires was largely dictated by the preparation method used, in that the hydrothermal treatment was beneficial to attain $\mathrm{TiO}_{2}$ nanowires with smaller diameter (Fig. 1e vs. d) and thus higher specific surface area ( $c f$. Table 1$)$.

\section{Effect of post-heat treatment on crystalline structure of $\mathrm{TiO}_{2}$ nanowires}

To optimize the calcination temperature in the post-heat treatment, TG-DTA combined analysis was performed on the $\mathrm{TiO}_{2}$ precursor nanowires, which are shown in Fig. 2. The initial weight loss until $c a .145{ }^{\circ} \mathrm{C}$ in the TG curve might be attributed to the evaporation of adsorbed water onto $\mathrm{H}_{2} \mathrm{Ti}_{3} \mathrm{O}_{7}$; accordingly, the DTA curve showed a significant endothermic peak ranging from $c a$. 60 to $145^{\circ} \mathrm{C}$ (peaking at $130.5^{\circ} \mathrm{C}$ ). The rest of weight loss occurred between 145 and $700{ }^{\circ} \mathrm{C}$, which may primarily be

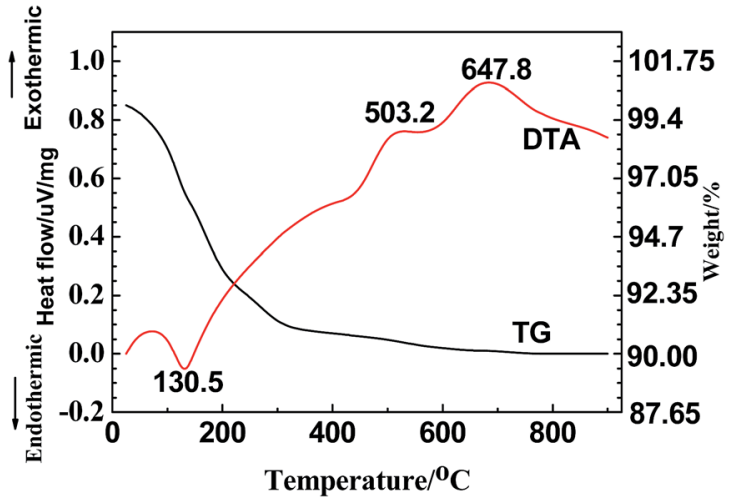

Fig. 2 Typical TG-DTA curves of the $\mathrm{H}_{2} \mathrm{Ti}_{3} \mathrm{O}_{7}$ (precursor of $\mathrm{TiO}_{2}$ ) nanowires.

due to the decomposition of $\mathrm{H}_{2} \mathrm{Ti}_{3} \mathrm{O}_{7}$ or further $\mathrm{TiO}_{2}$ and hydrated water, followed by the crystallization of the $\mathrm{TiO}_{2}$ nanowires. As the temperature was increased to $\sim 503.2{ }^{\circ} \mathrm{C}$, a weak exothermic peak was noted, probably representing the crystallization that led to the formation of the $\mathrm{TiO}_{2}-\mathrm{B}$. Furthermore, an exothermic peak appeared at $647.8{ }^{\circ} \mathrm{C}$, which was likely caused by the formation of the crystal structure of anatase phase. More specifically, the TG curve clearly demonstrates that there was a noticeable weight loss between 145 and $300{ }^{\circ} \mathrm{C}$ during the decomposition process, which presumably resulted from the dehydration of $\mathrm{H}_{2} \mathrm{Ti}_{3} \mathrm{O}_{7}$, as typically represented by eqn (1).

$$
\mathrm{H}_{2} \mathrm{Ti}_{3} \mathrm{O}_{7} \rightarrow 3 \mathrm{TiO}_{2}+\mathrm{H}_{2} \mathrm{O}
$$

According to eqn (1), the weight loss due to the $\mathrm{H}_{2} \mathrm{Ti}_{3} \mathrm{O}_{7}$ transformation into $\mathrm{TiO}_{2}$ should be $6.7 \%$; however, the actual weight loss from room temperature to $300{ }^{\circ} \mathrm{C}$ was $\sim 9 \%$ measured from the TG curve, which means that the content of the adsorbed water evaporated between 60 and $145{ }^{\circ} \mathrm{C}$ was about $2.3 \%$ in the $\mathrm{TiO}_{2}$-precursor nanowires. At higher temperatures above $300{ }^{\circ} \mathrm{C}$, the TG curve nearly leveled off due to the negligible weight loss during crystal growth and/or transformation of $\mathrm{TiO}_{2}$ nanowires.

To determine the structure of crystalline phase(s) of the $\mathrm{H}_{2} \mathrm{Ti}_{3} \mathrm{O}_{7} / \mathrm{TiO}_{2}$ nanowires, we performed XRD on the $\mathrm{TiO}_{2}$ precursor $\left(\mathrm{H}_{2} \mathrm{Ti}_{3} \mathrm{O}_{7}\right)$ nanowires (Sample A) (Fig. 3a), as well as on the $\mathrm{TiO}_{2}$ nanowires obtained from calcinations of the $\mathrm{TiO}_{2}$ precursor at $350{ }^{\circ} \mathrm{C}$ (Sample C), $450{ }^{\circ} \mathrm{C}$ (Sample D), $550{ }^{\circ} \mathrm{C}$ (Sample E) and $650{ }^{\circ} \mathrm{C}$ (Sample F) (Fig. 3b-e, respectively), as shown in Fig. 3. Fig. 3a indicates that the main crystallite of the precursor was the layered $\mathrm{H}_{2} \mathrm{Ti}_{3} \mathrm{O}_{7}$ structure(s), ${ }^{21}$ which could be converted to a $\mathrm{TiO}_{2}$ polymorph $\left(\mathrm{TiO}_{2}-\mathrm{B}\right)$ upon post-heat treatments ${ }^{22}$ as shown in Fig. 3b; further, the broadening of the diffraction peaks of the $\mathrm{TiO}_{2}$-precursor nanowires in Fig. 3a was presumably due to the small nanometer size of their crystallites, and/or to the bending of some atomic crystallographic plane(s) of the nanowires. ${ }^{21}$ Two new broad peaks emerged at $2 \theta$ values of $28.5^{\circ}$ and $43.8^{\circ}$, revealing the collapse (i.e. destruction) of the layered structure(s) of hydrogen titanates and the formation of $\mathrm{TiO}_{2}-\mathrm{B}^{23,24}$ (Fig. 3b and c). Compared with Fig. $3 \mathrm{~b}$ and c, there 


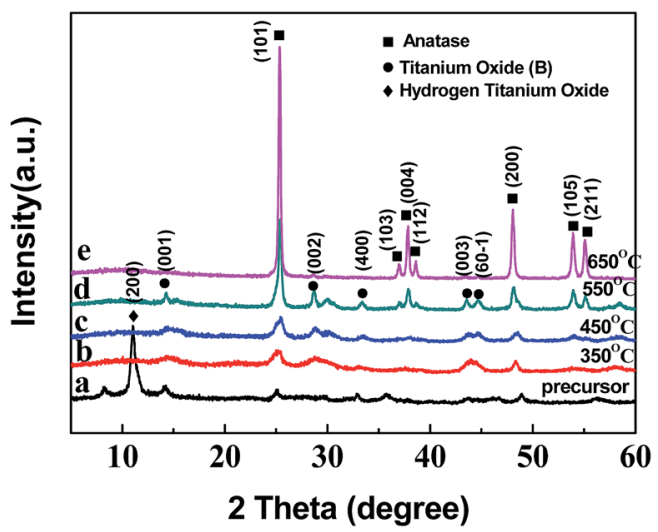

Fig. 3 XRD patterns of (a) the $\mathrm{H}_{2} \mathrm{Ti}_{3} \mathrm{O}_{7}$ (precursor of $\mathrm{TiO}_{2}$ ) nanowires and the $\mathrm{TiO}_{2}$ nanowires prepared from calcinations of the $\mathrm{TiO}_{2}$ precursor for $2 \mathrm{~h}$ at different temperatures $\left({ }^{\circ} \mathrm{C}\right.$ ): (b) 350; (c) 450; (d) 550; (e) 650.

appeared a pronounced new peak at $2 \theta=37.721^{\circ}$ in Fig. $3 \mathrm{~d}$, which, matching the (004) lattice planes of anatase, indicates the transformation from $\mathrm{TiO}_{2}-\mathrm{B}$ to anatase. ${ }^{25,26}$ In addition, the obvious diffraction peaks at $25.221^{\circ}, 36.861^{\circ}, 37.721^{\circ}$ and $38.641^{\circ}$ in Fig. 3d, respectively, corresponded to the (101), (103), (004) and (112) lattice planes of anatase, indicating the coexistence of $\mathrm{TiO}_{2}-\mathrm{B}$ and anatase at $550{ }^{\circ} \mathrm{C}$. These agree well with the TG-DTA observation (from Fig. 2) where a small exothermic peak located at $503.2{ }^{\circ} \mathrm{C}$ occurred in the DTA curve, which is characteristic of the $\mathrm{TiO}_{2}-\mathrm{B}$ crystal formation. Finally, with the further development of phase transformation upon an increase in the sintering temperature, as shown in Fig. 3e, the sharpened peak at $25.221^{\circ}$ was attributable to the strongest reflection from lattice-plane (101) of the $\mathrm{TiO}_{2}$-anatase phase, which suggests that Sample F primarily contained highly crystalline anatase.

In addition, Fig. 4 shows XRD patterns a and b of the $\mathrm{TiO}_{2}$ nanowires prepared from different post-heat treatments (calcination and hydrothermal, respectively) of the $\mathrm{TiO}_{2}$ precursor at $250{ }^{\circ} \mathrm{C}$ for $2 \mathrm{~h}$. The sharper diffraction peaks in Fig. $4 \mathrm{~b}$ demonstrate that, in comparison to the calcination (Fig. 4a), the

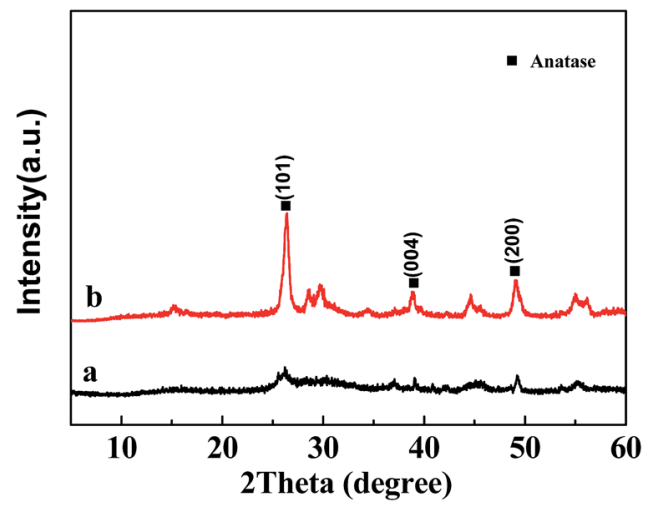

Fig. 4 XRD patterns of the $\mathrm{TiO}_{2}$ nanowires prepared by (a) the calcination and (b) the hydrothermal treatment of the $\mathrm{H}_{2} \mathrm{Ti}_{3} \mathrm{O}_{7}$ (precursor of $\mathrm{TiO}_{2}$ ) nanowires at $250{ }^{\circ} \mathrm{C}$ for $2 \mathrm{~h}$. hydrothermal treatment was more favorable for the formation and growth of anatase crystals.

\section{Effect of post-heat treatment on UV-Vis absorption}

Fig. 5a shows the UV-Vis absorbance spectra of Samples C, D, E and $\mathrm{F}$. The band gap energy $\left(E_{\mathrm{g}}\right)$ for direct gap semiconductors can be evaluated by using the Tauc equation, ${ }^{27,28}$

$$
\left(\alpha E_{\mathrm{p}}\right)^{0.5}=k\left(E_{\mathrm{p}}-E_{\mathrm{g}}\right)
$$

where $\alpha$ is the absorption coefficient, $E_{\mathrm{p}}$ the discrete photon energy $(h \nu)$, and $k$ absorption constants for indirect transitions. ${ }^{29,30}$ Plots of $\left(\alpha E_{\mathrm{p}}\right)^{0.5}$ versus $E_{\mathrm{p}}$ for the $\mathrm{TiO}_{2}$ nanowire membranes are shown in Fig. 5b; the corresponding $E_{\mathrm{g}}$ values were $2.98,2.94,2.90$ and $2.93 \mathrm{eV}$, respectively. When the temperature was increased from 350 to $550{ }^{\circ} \mathrm{C}$, the absorbance of UV and visible light was steadily enhanced (Fig. 5a). As shown in Fig. 3, the major crystalline phase of the $\mathrm{TiO}_{2}$ nanowires prepared from calcination of the $\mathrm{TiO}_{2}$ precursor at $350-550{ }^{\circ} \mathrm{C}$ was $\mathrm{TiO}_{2}$-B phase, with a small amount of anatase phase, and the content of anatase increased with an increase in the sintering temperature. Therefore, the increase in the absorption intensities of the $\mathrm{TiO}_{2}$ nanowires can be attributed to the increase in the content of anatase phase, which is consistent with other studies. ${ }^{2,5-8,15}$ With a further increase of the calcination temperature from 550 to $650{ }^{\circ} \mathrm{C}$, Sample F against Sample E possessed a significantly higher level of anatase ( $c f$. Fig. 3e vs. d), nevertheless with a relative reduction in its specific surface area
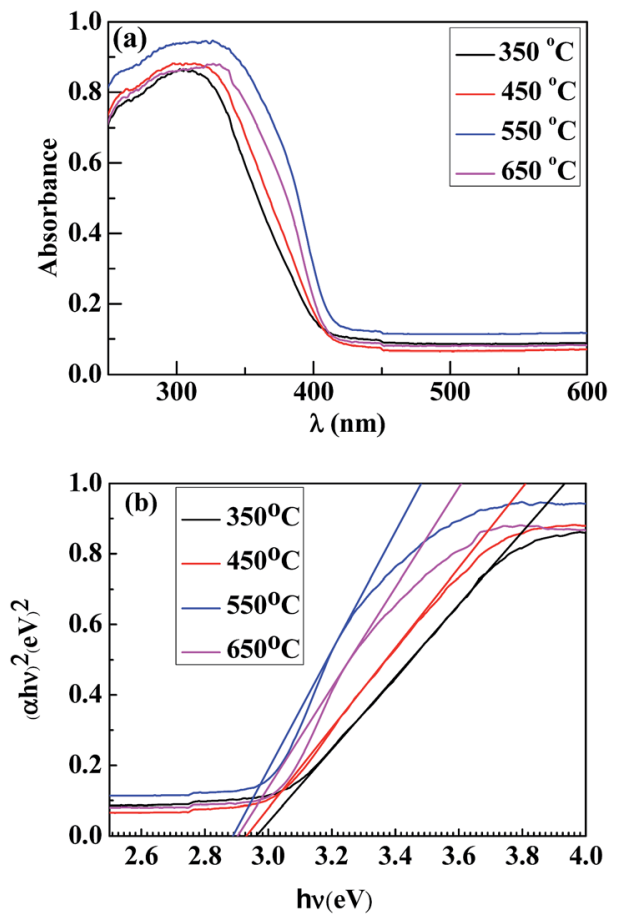

Fig. 5 (a) UV-Vis absorption spectra and (b) plots of $(\alpha h \nu)^{2} v s$. $h \nu$ for the $\mathrm{TiO}_{2}$ nanowires prepared from calcinations of the $\mathrm{H}_{2} \mathrm{Ti}_{3} \mathrm{O}_{7}$ (precursor of $\mathrm{TiO}_{2}$ ) nanowires for $2 \mathrm{~h}$ at different temperatures of $350,450,550$ and $650{ }^{\circ} \mathrm{C}$. 

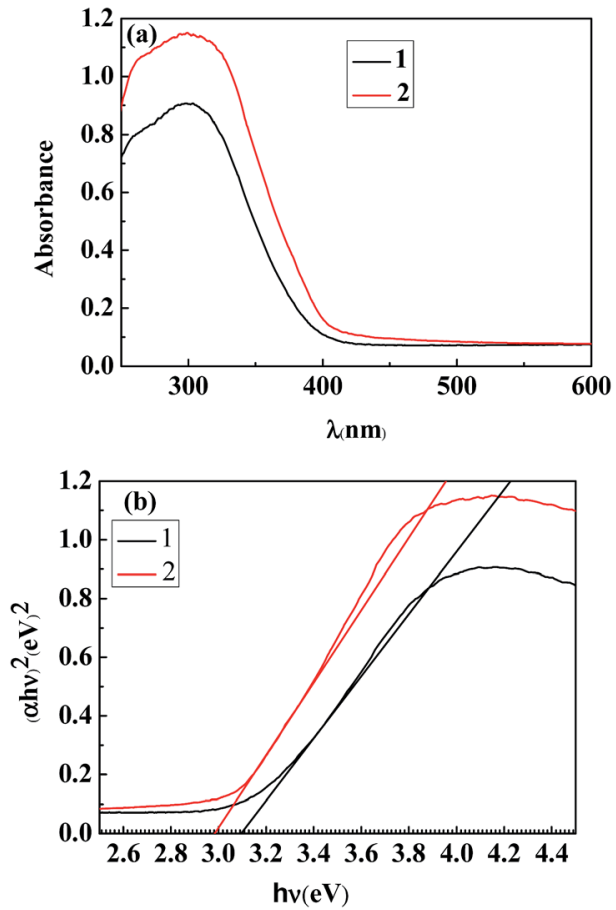

Fig. 6 (a) UV-Vis absorption spectra and (b) plots of $(\alpha h \nu)^{2} v s$. $h \nu$ for the $\mathrm{TiO}_{2}$ nanowires obtained by (1) the calcination and (2) the hydrothermal treatment of the $\mathrm{H}_{2} \mathrm{Ti}_{3} \mathrm{O}_{7}$ (precursor of $\mathrm{TiO}_{2}$ ) nanowires at $250{ }^{\circ} \mathrm{C}$ for $2 \mathrm{~h}$.

(cf. Table 1) which results in decreases in the UV-Vis absorption intensities as shown in Fig. $5 \mathrm{a}\left(550^{\circ} \mathrm{C} v s .650{ }^{\circ} \mathrm{C}\right)$. Given that a higher calcination temperature induces an increase in the content of anatase while a decrease in the specific surface area, we can come to the conclusion that the higher UV-Vis absorbances of Sample F than Sample E may be determined by the interactions of the two competing effects: that is, the effect of specific-surface-area decrease predominated over that of anatase-content increase.

The UV-Vis absorption spectra (Fig. 6a) were taken of the $\mathrm{TiO}_{2}$ nanowires obtained by the different post-heat treatments of the $\mathrm{TiO}_{2}$ precursor at $250{ }^{\circ} \mathrm{C}$, with Spectrum 1 representing the calcination and Spectrum 2 the hydrothermal treatment, from which the band-gap energy profiles were calculated (as shown in Fig. 6b). It is seen that, compared to the calcination method, the hydrothermal treatment of the $\mathrm{TiO}_{2}$ precursor resulted in a stronger light-absorption ability (Fig. 6a) and a narrower band gap (Fig. 6b) of the $\mathrm{TiO}_{2}$ nanowires, which could be attributed to a higher content of their highly crystalline anatase phase (Fig. 4) as well as their higher specific surface area (Fig. 1 and Table 1).

\section{Effect of post-heat treatment on photocatalytic activity of $\mathrm{TiO}_{2}$ nanowires}

The degradation curves (Fig. 7a), as well as kinetic curves (Fig. 7b) analyzed from Fig. $7 \mathrm{a}$, of the $\mathrm{TiO}_{2}$ nanowires were measured by monitoring the photocatalytic degradation of the RhB aqueous solution with Samples C, D, E and F, respectively,
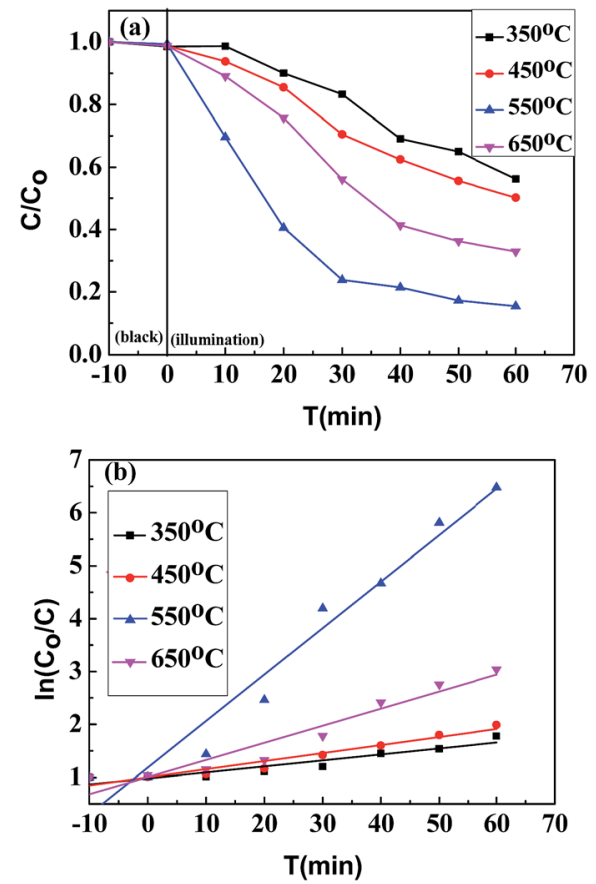

Fig. 7 (a) Degradation curves and (b) kinetic curves of a RhB aqueous solution of $5 \mathrm{mg} \mathrm{L}^{-1}$ that is photocatalytically degraded by the $\mathrm{TiO}_{2}$ nanowires prepared from the calcinations of the $\mathrm{H}_{2} \mathrm{Ti}_{3} \mathrm{O}_{7}$ (precursor of $\mathrm{TiO}_{2}$ ) nanowires for $2 \mathrm{~h}$ at different temperatures of 350 (Sample C), 450 (Sample D), 550 (Sample E) and $650{ }^{\circ} \mathrm{C}$ (Sample F).

as the photocatalysts. Prior to the measurements, the solution containing the catalyst sample was stirred at room temperature in the dark for $10 \mathrm{~min}$ to establish an adsorption/desorption equilibrium between the RhB-dye and the sample surfaces, and the photo-degradation efficiencies of the samples were found to be $44 \%, 50 \%, 85 \%$ and $64 \%$, respectively. The kinetic analysis by Fig. $7 \mathrm{~b}$ indicates that the photocatalytic reaction of Samples C, D and F followed a pseudo-first-order reaction, ${ }^{31}$ and the rate constants of RhB degradation by them were estimated to be $0.01127 \mathrm{~min}^{-1}, 0.01515 \mathrm{~min}^{-1}$, and $0.03228 \mathrm{~min}^{-1}$, respectively. It is notable that the photocatalytic activity of Sample E, exhibiting a maximum in the degradation efficiency, did not follow a pseudo-first-order mechanism. According to the previous studies, ${ }^{32}$ the photocatalytic activity of $\mathrm{TiO}_{2}$ can be identified as significant for aqueous pharmaceutical solutions interacting with nanomaterials through surface adsorption and photocatalytic degradation of the former by the latter; further, the surface adsorption for most of pharmaceuticals follows a pseudo-second-order model, whereas the photocatalytic degradation complies with a pseudo-first-order model. ${ }^{33}$ As held by the researchers, adsorption by $\mathrm{TiO}_{2}$ nanomaterials actually is not only surface adsorption behavior, which also depends on complicated factors such as surface charge of nanomaterials, adsorbent masses, ambient $\mathrm{pH}$ values, etc.; generally, the adsorptive capacity of $\mathrm{TiO}_{2}$ nanomaterials is nearly saturated during $30 \mathrm{~min} .{ }^{34}$ But notably, the time intervals of adsorption/ desorption equilibrium between the RhB-dye and the surfaces of Samples C, D, E and F were invariably $10 \mathrm{~min}$ in this study, 
which indicates that it was possible for some kinds of samples (Samples C, D and F) to obtain an adsorption/desorption equilibrium in the $10 \mathrm{~min}$, whereas that the other sample (Sample E) did not. Due to its unsaturated adsorptive capacity, the photocatalytic activity of Sample $\mathrm{E}$ after the treatment in the dark for 10 min might probably be determined by a coupling of the surface adsorption (ruled by the pseudo-second-order model) and the photocatalytic degradation (ruled by the pseudo-first-order model). The synergistic decoloration of the RhB aqueous solution by both the surface adsorption and the photocatalytic degradation resulted in the inappropriateness to plot linearly as a pseudo-first-order model. However, the data beyond 30 min shown in Fig. 7b, which reflects the near saturation of adsorptive capacity of Sample E, can be well fitted by the pseudo-first-order formula.

Again, degradation curves (Fig. 8a), and kinetic curves (Fig. 8b) obtained from Fig. 8a, were plotted to compare RhB degradation efficiencies by the $\mathrm{TiO}_{2}$ nanowires obtained by the different post-heat treatments (calcinations $v s$. hydrothermal) of the $\mathrm{TiO}_{2}$ precursor at $250{ }^{\circ} \mathrm{C}$. Similarly, the hydrothermal kinetic plot of Sample G (Fig. 8b) was apparently nonlinear, the rationale behind which was also the synergistic decoloration of the RhB aqueous solution through both the surface adsorption and the photocatalytic degradation of RhB by Sample G. Compared to the calcination at $250{ }^{\circ} \mathrm{C}$, the hydrothermal treatment at the same temperature led to a higher RhB degradation efficiency ( $60 \%$ vs. $38 \%$ ), which was comparable to that (64\%) of Sample $\mathrm{F}$ that was formed from calcination of the precursor at $650{ }^{\circ} \mathrm{C}$. This probably is due to the fact that the
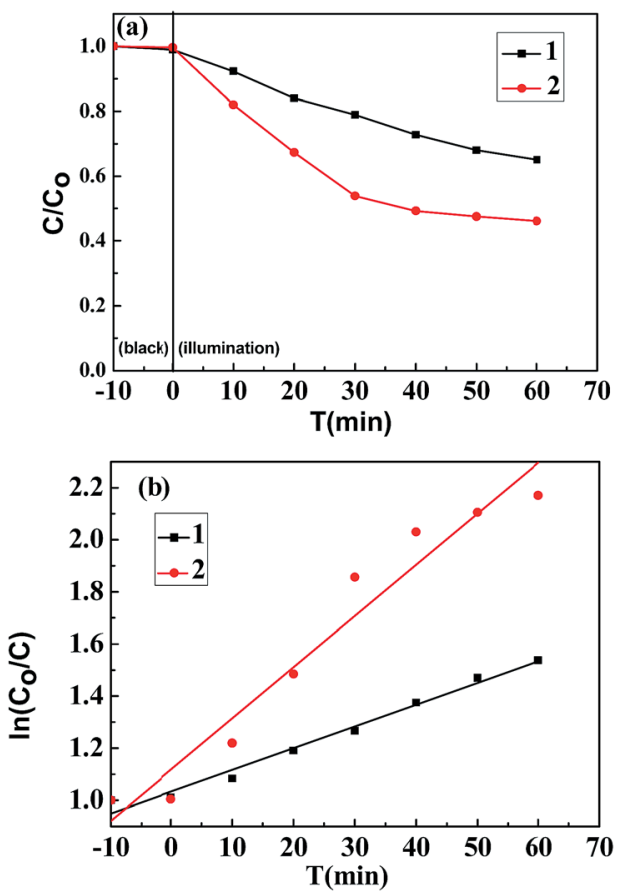

Fig. 8 (a) Degradation curves and (b) kinetic curves of a RhB aqueous solution of $5 \mathrm{mg} \mathrm{L}^{-1}$ that is photocatalytically degraded by the $\mathrm{TiO}_{2}$ nanowires prepared from (1) the calcinations (Sample B) and (2) the hydrothermal treatment (Sample $\mathrm{G}$ ) of the $\mathrm{H}_{2} \mathrm{Ti}_{3} \mathrm{O}_{7}$ (precursor of $\mathrm{TiO}_{2}$ ) nanowires at $250{ }^{\circ} \mathrm{C}$ for $2 \mathrm{~h}$. sample treated with the hydrothermal method (Sample G) had a higher proportion of anatase phase ( $c f$. Fig. 4) as well as a higher specific surface area ( $c f$. Fig. 1 and Table 1), which favored an enhancement of photocatalytic activity relative to the calcinated sample (Sample B) (cf. Fig. 8).

Moreover, TEM and HRTEM were also used to study the fine structure of Sample G as shown in Fig. 9a and b, respectively. Fig. 9a unveils a typical morphology of the $\mathrm{TiO}_{2}$ nanowires: the average diameter of the nanowire sample was approximately $60 \mathrm{~nm}$; and the corresponding SAED (the inset in Fig. 9a) reveals that the $\mathrm{TiO}_{2}$ nanowires had a near single crystal anatase structure, which was consistent with the XRD result (Pattern b of Fig. 4). Furthermore, the near single-crystalline structure was further confirmed by the HRTEM image (shown in Fig. 9b): Fig. 9b shows that the distance between adjacent lattice fringes was $c a .0 .35 \mathrm{~nm}$, which could be assigned to the interplanar spacing of the $\mathrm{TiO}_{2}$ anatase (101)

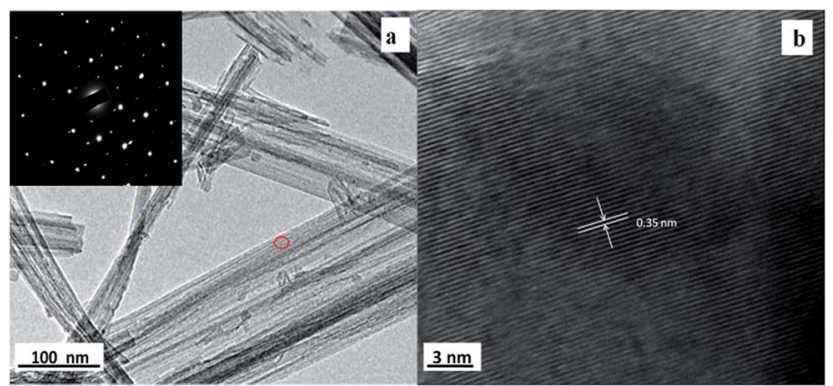

Fig. 9 (a) A TEM image of Sample G (prepared by hydrothermal treatment of the $\mathrm{TiO}_{2}$ precursor at $250{ }^{\circ} \mathrm{C}$ ), where the inset shows an SAED image of the $\mathrm{TiO}_{2}$ nanowires; (b) the corresponding HRTEM image of the area red-circled in (a), from which an interspacing of $0.35 \mathrm{~nm}$ was resolved for the (101) crystallographic plane of $\mathrm{TiO}_{2}$ anatase phase.

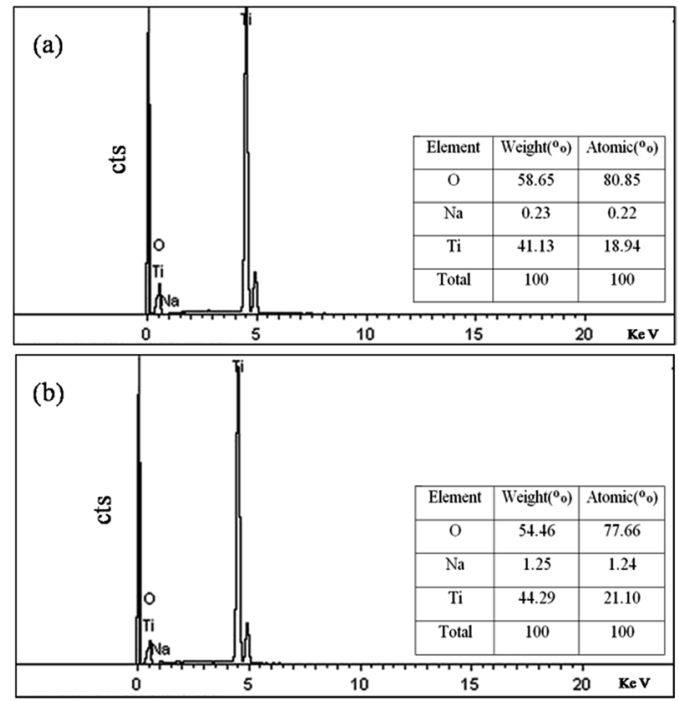

Fig. 10 Energy dispersive $\mathrm{X}$-ray (EDX) spectra of the $\mathrm{TiO}_{2}$ nanowires prepared from the different post-heat treatments of the $\mathrm{H}_{2} \mathrm{Ti}_{3} \mathrm{O}_{7}$ (precursor of $\mathrm{TiO}_{2}$ ) nanowires at $250{ }^{\circ} \mathrm{C}$ for $2 \mathrm{~h}$ : (a) the hydrothermal treatment; (b) the calcination. 
planes; this corroborates the formation of anatase $\mathrm{TiO}_{2}$ nanowires in our experiments.

In addition, as shown in Fig. 10, Sample G against Sample B had a remarkably higher ratio of the Ti and $\mathrm{O}$ combined content to the Na level; this suggests that the hydrothermal method, making the $\mathrm{Na}^{+}$-ion impurity diffuse effectively into the water phase, increased the purity of the formed $\mathrm{TiO}_{2}$ nanowires, which also contributed to the increase of their photocatalytic activity.

\section{Conclusions}

This work has detailed the synthesis of $\mathrm{TiO}_{2}$ nanowires (membranes) on a titanium foil substrate via a three-step route: (1) hydrothermal growth of $\mathrm{Na}_{2} \mathrm{Ti}_{3} \mathrm{O}_{7}$ from $\mathrm{Ti}$ substrate in a concentrated $\mathrm{NaOH}$ aqueous solution; (2) exchange of $\mathrm{Na}^{+}$ ions with $\mathrm{H}^{+}$to form $\mathrm{H}_{2} \mathrm{Ti}_{3} \mathrm{O}_{7}$; and (3) post-heat treatment (i.e. annealing) of the $\mathrm{H}_{2} \mathrm{Ti}_{3} \mathrm{O}_{7}$ precursor by calcination at different temperatures $\left(250,350,450,550\right.$ and $\left.650{ }^{\circ} \mathrm{C}\right)$ or by hydrothermal treatment $\left(250{ }^{\circ} \mathrm{C}\right)$.

Morphological characterizations by the FE-SEM have revealed that the $\mathrm{TiO}_{2}$ nanowires synthesized from the hydrothermal have a significantly smaller diameter and hence a higher specific surface area than those from the calcination. The TG-DTA, TEM and XRD results have indicated that a calcination temperature of $\mathrm{ca}$. $550{ }^{\circ} \mathrm{C}$ maximally contributes to the formation and growth of anatase crystals with a relative reduction in the specific surface area of the $\mathrm{TiO}_{2}$ nanowires, and that the hydrothermal favors an enhancement of $\mathrm{TiO}_{2}$-nanowire crystallinity, especially for the anatase phase. UV-Vis absorption spectra and their associated band-gap energy profiles have uncovered that the $\mathrm{TiO}_{2}$ nanowires, prepared from calcination of the $\mathrm{TiO}_{2}$ precursor at $550{ }^{\circ} \mathrm{C}$, have maxima in UV-Vis absorption intensities as well as the narrowest band-gap among those calcinated at the other temperatures. EDX spectrometry has demonstrated that, due to the diffusion of $\mathrm{Na}^{+}$impurity into the water phase, the hydrothermal forms much purer $\mathrm{TiO}_{2}$ nanowires than the calcination.

The photocatalytic degradation of an RhB aqueous solution has been investigated by the $\mathrm{TiO}_{2}$ nanowires synthesized from the calcination and the hydrothermal methods. Assays have demonstrated that the $\mathrm{TiO}_{2}$ nanowires obtained by calcination at an optimum temperature of $550{ }^{\circ} \mathrm{C}$ exhibit a maximum in photocatalytic activity compared with the other $\mathrm{TiO}_{2}$ nanowires calcinated at 350,450 and $650{ }^{\circ} \mathrm{C}$, presumably owing to a combination of the effects of anatase-content increase and of specific-surface-area decrease with increasing the calcination temperature. At the same temperature of $250{ }^{\circ} \mathrm{C}$, the hydrothermal produces $\mathrm{TiO}_{2}$ nanowires of markedly higher photocatalytic activity than the calcinations, primarily due to their significantly higher specific surface area, degree of crystallinity, and purity (from a much decreased $\mathrm{Na}^{+}$-impurity content).

\section{Acknowledgements}

The authors gratefully acknowledge the financial support for this work from the State Key Development Program for Basic
Research of China (Contract no. 2010CB635107), the National Natural Science Foundation of China (NSFC) (Contract no. 51004046, 51202064 and 51302073), the Natural Science Foundation of the Hubei province of China (Contract no. 2010CDB05806), the Wuhan Youth Chenguang Program of Science and Technology (Contract no. 2013070104010016) and Middle-aged and Young program of Educational Commission of Hubei Province (Q20101409).

\section{References}

1 A. Kubacka, M. Fernández-García and G. Colón, Chem. Rev., 2011, 112, 1555.

2 M. A. Henderson and I. Lyubinetsky, Chem. Rev., 2013, 113, 4428.

3 Y. Du, R. Z. Chen, J. F. Yao and H. T. Wang, J. Alloys Compd., 2013, 551, 125.

4 Y. Liao, C. Xie, Y. Liu, H. Chen, H. Li and J. Wu, Ceram. Int., 2012, 38, 443.

5 W. J. Ong, L. L. Tan, S. P. Chai, S. T. Yong and A. R. Mohamed, ChemSusChem, 2014, 7, 690.

6 A. Hu, X. Zhang, K. D. Oakes, P. Peng, Y. N. Zhou and M. R. Servos, J. Hazard. Mater., 2011, 189, 278.

7 X. Chen and A. Selloni, Chem. Rev., 2014, 114, 9281.

8 K. Nakata and A. Fujishima, J. Photochem. Photobiol., C, 2012, 13, 169.

9 H. S. Kim, J. W. Lee, N. Yantara, P. P. Boix, S. A. Kulkarni, S. Mhaisalkar, M. Grätzel and N. G. Park, Nano Lett., 2013, 13, 2412.

10 Q. Xiang, J. Yu and M. Jaroniec, J. Am. Chem. Soc., 2012, 134, 6575.

11 K. Shankar, J. Basham, N. Allam, O. Varghese, G. Mor, X. Feng, M. Paulose, J. Seabold, K. Choi and C. Grimes, J. Phys. Chem. C, 2009, 113, 6327.

12 D. R. Baker and P. V. Kamat, J. Phys. Chem. C, 2009, 113, 17967.

13 S. Banerjee, S. K. Mohapatra and M. Misra, J. Phys. Chem. C, 2011, 115, 12643.

14 X. Lu, G. Wang, T. Zhai, M. Yu, J. Gan, Y. Tong and Y. Li, Nano Lett., 2012, 12, 1690.

15 J. Pan, G. Liu, G. Q. Lu and H. M. Cheng, Angew. Chem., Int. Ed., 2011, 50, 2133.

16 H. Li, X. F. Li, C. Y. Zhang, S. L. Tie and S. Lan, Appl. Surf. Sci., 2017, 396, 221.

17 Y. C. Yao, X. R. Dai, X. Y. Hu, S. Z. Huang and Z. Jin, Appl. Surf. Sci., 2016, 387, 469.

18 Y. Q. Wang, W. H. Han, B. Zhao, L. L. Chen, F. Teng, X. D. Li, C. T. Gao, J. Y. Zhou and E. Q. Xie, Sol. Energy Mater. Sol. Cells, 2015, 140, 376.

19 L. F. Que, Z. Lan, W. X. Wu, J. H. Wu, J. M. Lin and M. L. Huang, J. Power Sources, 2014, 266, 440.

20 Y. Q. Wang, L. Gu, Y. G. Guo, H. Li, X. Q. He, S. Tsukimoto, Y. Ikuhara and L. J. Wan, J. Am. Chem. Soc., 2012, 134, 7874.

21 Q. Chen, G. H. Du, S. Zhang and L. M. Peng, Acta Crystallogr., Sect. B: Struct. Sci., 2002, 58, 587.

22 T. P. Feist and P. K. Davies, J. Solid State Chem., 1992, 101, 275. 
23 S. Pavasupree, Y. Suzuki, S. Yoshikawa and R. Kawahata, J. Solid State Chem., 2005, 178, 3110.

24 R. Ma, Y. Bando and T. Sasaki, J. Phys. Chem. B, 2004, 108, 2115.

25 A. R. Armstrong, G. Armstrong, J. Canales and P. G. Bruce, Angew. Chem., Int. Ed., 2004, 43, 2286.

26 Z. Yuan and B. Su, Colloids Surf., A, 2004, 241, 173.

27 Y. Ren, Z. Liu, F. Pourpoint, A. R. Armstrong, C. P. Grey and P. G. Bruce, Angew. Chem., 2012, 124, 2206.

28 M. Ye, J. Gong, Y. Lai, C. Lin and Z. Lin, J. Am. Chem. Soc., 2012, 134, 15720.

29 N. Serpone, D. Lawless and R. Khairutdinov, J. Phys. Chem., 1995, 99, 16646.
30 X. H. Wang, J. G. Li, H. Kamiyama, M. Katada, N. Ohashi, Y. Moriyoshi and T. Ishigaki, J. Am. Chem. Soc., 2005, 127, 10982.

31 P. V. Kamat, J. Phys. Chem. C, 2012, 116, 11849.

32 W. Fan, Q. Lai, Q. Zhang and Y. Wang, J. Phys. Chem. C, 2011, 115, 10694.

33 R. Liang, A. Hu, W. Li and Y. Zhou, J. Nanopart. Res., 2013, 15, 1990.

34 A. Hu, R. Liang, X. Zhang, S. Kurdi, D. Luong, H. Huang, P. Peng, E. Marzbanrad, K. D. Oakes, Y. Zhou and M. R. Servos, J. Photochem. Photobiol., A, 2013, 256, 7. 